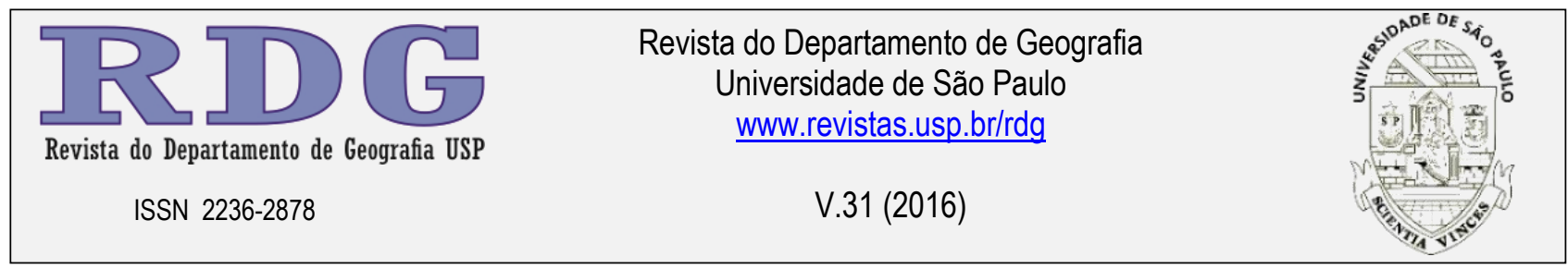

\title{
CARACTERÍSTICAS DA PRECIPITAÇÃO PLUVIAL E A EROSIVIDADE DAS CHUVAS NA VERTENTE PARANAENSE DA BACIA HIDROGRÁFICA DO RIO ITARARÉ
}

\author{
CHARACTERISTICS OF RAINFALL AND THE RAINFALL EROSIVITY \\ OF THE PARANA STATE SLOPE OF THE ITARARÉ WATERSHED
}

\author{
Paulo Miguel de Bodas Terassi \\ Universidade de São Paulo \\ pmbterassi@usp.br
}

Carlos Henrique da Graça

Universidade Estadual de Maringá

José Tadeu Garcia Tommaselli

Universidade Estadual Paulista "Júlio de Mesquita Filho"

Recebido (Received): 09/03/2016_Aceito (Accepted): 17/06/2016

DOI: http://dx.doi.org/10.11606/rdg.v31i0.112021

\begin{abstract}
Resumo: Informações sobre do potencial erosivo das chuvas são necessárias para a prevenção e controle da degradação do solo, bem como no planejamento e desenvolvimento de bacias hidrográficas em regiões tropicais. O presente trabalho objetivou caracterizar a precipitação pluvial e quantificar o poder erosivo das chuvas na vertente paranaense da bacia hidrográfica do rio Itararé, dada a relevância para o manejo adequado e a aplicação de práticas preditivas a perda de solos. Foram obtidos os dados de treze postos pluviométricos e de uma estação meteorológica, de Joaquim Távora, pertencente ao Instituto Agronômico do Paraná, para a série histórica de 1976 a 2012. O índice de erosividade da chuva foi calculado utilizando-se uma equação do tipo $a+b x$, no qual a e $b=$ coeficientes linear e angular, e $x=p^{2} / P(p-$ precipitação média mensal em milímetros; $\mathrm{P}$ - precipitação média anual em milímetros). Os resultados indicaram que o verão e a primavera caracterizam-se por apresentar a maior suscetibilidade a erosividade das chuvas devido a uma concentração de 70,8\% dos valores anuais. Foram obtidas quatro regiões homogêneas quanto ao potencial erosivo das chuvas, demonstrando as relações entre a orografia e a dinâmica atmosférica regional.
\end{abstract}

Palavras-chave: pluviosidade; potencial erosivo; bacia hidrográfica; perdas de solo.

\begin{abstract}
Information about the rainfall erosive potential are necessary for the prevention and control of soil degradation as well as the planning and development of watersheds in tropical regions. This study aimed to characterize the rainfall and quantify the rainfall erosive power in Paraná slope of the Itararé watershed, given the importance for proper management and application of predictive practices soil losses. Were obtained rainfall data of thirteen rain gauge stations and the weather station Joaquim Távora, which belongs to the Agronomic Institute of Paraná, for the historical data serie to 1976-2012. The rainfall erosivity index was calculated using an equation of the type $a+b x$, which $a$ and $b=$ linear and angular coefficients, $x=p^{2} / P$ ( $p$ - average monthly rainfall in mm; $P$ - average annual rainfall in millimeters). The results indicated that the summer and spring are characterized by having the greatest susceptibility to rainfall erosivity due to a concentration of $70.8 \%$ of the annual values. Were obtained four homogeneous as the rainfall erosive potential, proving the relationship between orography and regional atmospheric dynamic.
\end{abstract}

Keywords: rainfall; erosive potential; watershed; soil losses. 


\section{INTRODUÇÃO}

Uma das principais características da pluviosidade é o seu potencial em ocasionar erosões. A erosão pode ser entendida como produto final da interação chuva/solo e é, portanto, uma resultante do poder da chuva em causar erosão e da capacidade do solo em resistir. O poder da chuva em causar erosão é denominado erosividade, que é função de suas características físicas. Para Stocking (1977) e Guerra (2010), existem vários parâmetros que podem ser utilizados para medir a erosividade da chuva, destacando: o total de precipitação, a intensidade da chuva, o momento e a energia cinética.

A erosividade da chuva é obtida pelo produto entre a energia cinética total da chuva (E) e a sua intensidade máxima em 30 min $\left(\mathrm{I}_{30}\right)$. O parâmetro de erosividade $\mathrm{EI}_{30}$ foi desenvolvido nos Estados Unidos por Wischmeier e Smith (1958) e tem sido calculado e testado em diversos países com algumas limitações. Em parte, essas limitações podem estar associadas a falta de dados confiáveis e, também, a mensuração que depende de análises morosas e trabalhosas de diagramas pluviográficos (BERTONI e LOMBARDI NETO, 2012). A partir disso, diversos autores passaram a correlacionar o índice de erosão com fatores climáticos, fatores esses de fácil medida (dados pluviométricos) e que não requerem registros de intensidade de chuva (FOURNIER, 1960; HUDSON, 1977). Esta alternativa, embora apresente limitações por não utilizar as intensidades das precipitações, tem proporcionado uma ampliação nas estimativas da erosividade em diversas regiões brasileiras (LEPRUN, 1981; MORAIS et al. 1991; LOMBARDI e MOLDENHAUER, 1992; RUFINO et al 1993; SILVA et al., 2010, OLIVEIRA et al. (2012); WALTRICK et al., 2015). A respeito disso, Silva (2004) investigou a distribuição da erosividade para o Brasil com a utilização de 1.600 estações meteorológicas e verificou elevados valores para quase todo o território nacional, com exceção do semiárido nordestino. Os maiores valores foram obtidos nos meses de janeiro e dezembro, com uma redução significativa entre junho e setembro, em consonância com as características de distribuição da pluviosidade do Brasil Tropical.

O conhecimento das relações entre os fatores que causam as perdas de solo e o que permitem reduzi-las é de fundamental importância para planejar ações conservacionistas adequadas e econômicas e elaborar projetos de controle da degradação do solo, bem como os relacionados ao planejamento e desenvolvimento de bacias hidrográficas em regiões tropicais, onde o regime pluviométrico concentrado estabelece um fator determinante para as maiores perdas de solo e, consequentemente, para a aceleração de processos erosivos que determinam a menor disponibilidade dos recursos hídricos (ZHANG et al., 2005; UFOEGBUENE et al., 2011).

O recorte de estudo do presente trabalho corresponde a vertente paranaense da bacia hidrográfica do rio Itararé, um dos mais importantes tributários do rio Paranapanema, onde se encontra a represa de Chavantes construída durante a instalação da Usina Hidrelétrica de Chavantes no ano de 1971. O reservatório da usina apresenta uma área de $400 \mathrm{~km}^{2}$ e um perímetro de $1.085 \mathrm{~km}^{2}$ (TOYAMA, 2014). Devido sua vasta área são comuns relatos de enchentes, deslizamentos superficiais de encostas, processos erosivos e assoreamento das margens dos mananciais e do reservatório (DUKE ENERGY, 2012). Segundo Cabral et al. (2005), Cabral et al. (2007) e Rubio (2014), a erosividade das chuvas corresponde a um dos principais fatores para a gênese e o desenvolvimento das feições erosivas nas margens dos reservatórios.

A agropecuária é um segmento com relevante participação na gestão dos recursos hídricos. Os períodos de plantio entre safras apresentam elevada vulnerabilidade ao impacto de eventos pluviométricos erosivos, uma vez que a exposição do solo e a baixa proteção de plantas ainda em desenvolvimento aumentam as probabilidades de remoção de porções de solos e a formação de ravinamentos e voçorocas (ARAI et al., 2010). As pastagens podem representar um problema ambiental com a pecuária intensiva ou rotativa e a consequente compactação do solo gerada pelo deslocamento dos rebanhos de animais (INÁCIO et al., 2007). O solo compactado dificulta a infiltração da água e aumenta o escoamento superficial, podendo gerar erosões, especialmente em condições de chuvas intensas e de elevado potencial erosivo. 
Diante disso, o presente trabalho objetivou caracterizar a precipitação pluvial e quantificar o potencial erosivo das chuvas na vertente paranaense da bacia hidrográfica do rio Itararé, dada a relevância para o manejo adequado e a aplicação de práticas preditivas a perda de solos, tanto para o planejamento ambiental quanto para o planejamento agrícola, visando à manutenção da qualidade do solo e da água. Escolheu-se a equação de Rufino et al. (1993) por sua eficácia na adequação ao regime pluviométrico regional e pela continuidade de sua aplicação em trabalhos posteriores (SILVA, 2004; OLIVEIRA et al., 2012; WALTRICK et al., 2015).

\section{MATERIAIS E MÉTODOS}

A porção paranaense da bacia hidrográfica do rio Itararé está situada entre os Primeiro, Segundo e Terceiro Planaltos Paranaenses (MAACK, 2012). A área da bacia abrange uma superfície aproximada de $4.845 \mathrm{~km}^{2}$ (ITCG, 2013) e localiza-se nos setores nordeste do estado do Paraná. O curso principal compreende um divisor natural com o estado de São Paulo, tendo sua nascente no município de Sengés a uma altitude aproximada de 1.060 metros (Figura 1).

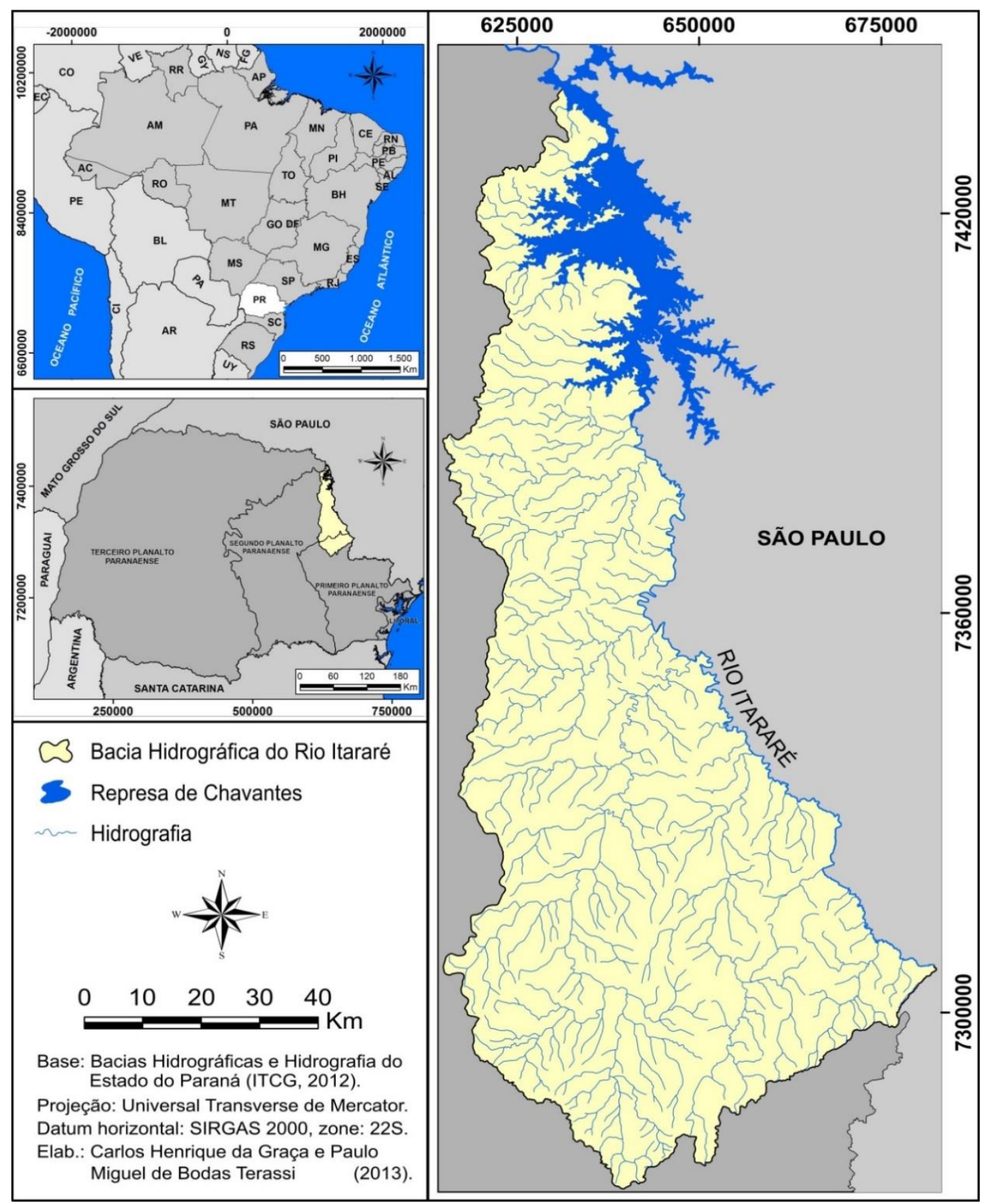

Figura 1: Localização da vertente paranaense da bacia hidrográfica do rio Itararé. 
Os dados pluviométricos utilizados no trabalho foram obtidos de treze postos pluviométricos gerenciados pelo Instituto das Águas do Paraná e da estação meteorológica da rede do IAPAR (Instituto Agronômico do Paraná), no município de Joaquim Távora, para a série histórica entre 1976 a 2012. Os dados dos postos pluviométricos que estão ao entorno da bacia hidrográfica foram utilizados na busca de uma melhor distribuição espacial da precipitação pluviométrica e para o preenchimento de eventuais dados faltantes (Quadro 1).

Quadro 1: Localização geográfica dos postos pluviométricos e da estação Meteorológica* na vertente paranaense da bacia hidrográfica do rio Itararé.

\begin{tabular}{c|c|c|c|c|c}
\hline $\begin{array}{c}\text { Número no } \\
\text { mapa de } \\
\text { localização }\end{array}$ & $\begin{array}{c}\text { Código da } \\
\text { ANEEL }\end{array}$ & $\begin{array}{c}\text { Posto Pluviométrico/ } \\
\text { Estação Meteorológica }\end{array}$ & $\begin{array}{c}\text { Latitude } \\
\mathbf{( N m )}\end{array}$ & $\begin{array}{c}\text { Longitude } \\
(\mathbf{E m})\end{array}$ & $\begin{array}{c}\text { Altitude } \\
\mathbf{( m )}\end{array}$ \\
\hline 1 & 02349060 & Carlópolis (Nova Brasília) & 7395526 & 627900 & 563 \\
\hline 2 & 02449030 & Castro (Fazenda Marão) & 7275043 & 633292 & 1100 \\
\hline 3 & 02449021 & Doutor Ulysses (Varzeão) & 7282084 & 660061 & 818 \\
\hline 4 & 02449036 & $\begin{array}{c}\text { Jaguariaíva } \\
\text { (Eduardo Xavier da Silva) }\end{array}$ & 7302629 & 643698 & 1000 \\
\hline 5 & 02449040 & Jaguariaíva & 7317956 & 630287 & 890 \\
\hline $6^{*}$ & 02349030 & Joaquim Távora* & 7400672 & 615718 & 512 \\
\hline 7 & 02449011 & Piraí do Sul & 7286806 & 608541 & 1068 \\
\hline 8 & 02449032 & Piraí do Sul (Capinzal) & 7289831 & 629085 & 1026 \\
\hline 9 & 02349036 & Ribeirão Claro & 7433790 & 627919 & 782 \\
\hline 10 & 02349061 & Santana do Itararé & 7372279 & 640380 & 543 \\
\hline 11 & 02349064 & São José da Boa Vista & 7354589 & 637409 & 550 \\
\hline 12 & 02449045 & São José da Boa Vista & 7337733 & 637247 & 850 \\
\hline 13 & 02449044 & (Barra Mansa) & 7333850 & 655848 & 650 \\
\hline 14 & 02349033 & Sengés & 7371211 & 606992 & 483 \\
\hline & \multicolumn{3}{|c}{ Tomazina } & & \\
\hline
\end{tabular}

Foram verificadas falhas de dados inferiores a 5\% da série histórica, que foram preenchidas seguindo o método de ponderação regional apresentado por Villela e Mattos (1975), considerado um dos mais adequados para dados meteorológicos (OLIVEIRA et al., 2010). Esse método tem como base o registro pluviométrico de três postos localizados o mais próximo possível do posto em que se verifica a falta de dados, com características pluviométricas (distribuição mensal) e altitudes semelhantes. Considerando x o posto que apresente a falha e por A, B e C os postos vizinhos, é possível determinar a precipitação (Px) desse posto x pela média ponderada do registro dos três postos vizinhos, onde os pesos são as razões entre as precipitações anuais normais (Equação 1).

$$
\mathrm{Px}=\frac{\overline{\mathrm{Px}}}{3}\left(\frac{\mathrm{Pa}}{\overline{\mathrm{Pa}}}+\frac{\mathrm{Pb}}{\overline{\mathrm{Pb}}}+\frac{\mathrm{Pc}}{\overline{\mathrm{Pc}}}\right)
$$

Onde: $\mathrm{x}$ é o posto pluviométrico ou estação meteorológica com dados pluviométricos faltantes; Px é a precipitação do mês faltante; $\overline{\mathrm{Px}}$ é a precipitação média mensal da estação x; $\mathrm{Pa}, \mathrm{Pb}, \mathrm{Pc}$ são as precipitações mensais reais dos postos pluviométricos selecionados para o preenchimento; e $\overline{\mathrm{Pa}}, \overline{\mathrm{Pb}}, \overline{\mathrm{Pc}}$ são as precipitações médias mensais destes mesmos postos.

Para a manipulação e organização das informações foi realizado tratamento dos dados de precipitação utilizando de parâmetros estatísticos básicos em planilha eletrônica Microsoft Office Excel 2007. Ressalva-se que para a escala sazonal os meses foram delimitados conforme o ano civil, com os meses de janeiro, fevereiro e março agrupados como o verão, abril, maio e junho como meses de outono, julho, agosto e setembro como meses de inverno, outubro, novembro e dezembro como meses de primavera. 
O índice de erosividade da chuva foi calculado utilizando os dados de precipitação média mensal e média anual para a área de estudo, aplicando a equação do tipo $\mathrm{Y}=\mathrm{a}+\mathrm{bx}$, onde: $\mathrm{Y}=$ índice de erosão (MJ.mm.ha ${ }^{-1} \cdot \mathrm{h}^{-1} \cdot \mathrm{ano}^{-1}$ ); a e $\mathrm{b}=$ coeficientes linear e angular, e $\mathrm{x}=\mathrm{p}^{2} / \mathrm{P}$, apresentada por Rufino, Biscaia e Merten (1993) na identificação de regiões isoerosivas para o estado do Paraná. Os valores atribuídos nesse estudo encontram-se na região isoerosiva $7(\mathrm{Y}=9,51+4,20 \mathrm{x})$, que deu parâmetro para a Equação 2.

$$
\mathrm{EI}_{\mathrm{m}}=9,51+4,20\left(\frac{\mathrm{p}^{2}}{\mathrm{P}}\right)^{* 9,80665}
$$

Onde: $\mathrm{EI}_{\mathrm{m}}$ - Índice mensal de erosividade da chuva em MJ.mm.ha ${ }^{-1} \cdot \mathrm{h}^{-1} \cdot \mathrm{mês}^{-1} ; \mathrm{a}$ - coeficiente linear; $\mathrm{b}$ coeficiente angular; p - Precipitação média mensal em milímetros; P - Precipitação média anual em milímetros; 9, 80665 - Conversão Kgf.m para MJ.

Como os valores do índice erosão calculados para cada estação pluviométrica são expressos na escala mensal, foi necessária a soma dos índices mensais para obtenção dos valores anuais.

Para a elaboração das cartas de distribuição da precipitação pluviométrica e do índice de erosão das chuvas da área de estudo, utilizou-se o software Surfer versão 7.0 aplicando o método reticulado, para realizar a interpolação de dados, com os quais foram gerados os valores para a construção das isolinhas. A interpolação dos dados no reticulado do programa foi feita através do interpolado Kriging, considerado o mais adequado para este tipo de análise, pois possibilita a melhor representação da continuidade dos fenômenos geográficos, destacando, especificamente, sua eficiência na representação da por apresentar uma menor dependência espacial (CARVALHO e ASSAD, 2005) e eficácia com o modelo semivariograma esférico, com uma menor quantidade de núcleos isolados (GARDIMAN JÚNIOR et al., 2012).

Após a análise espacial da pluviosidade e da erosividade nas escalas anual e sazonal, realizouse o emprego da técnica de agrupamento, especificamente para os resultados mensais, com o objetivo de sintetizar e compreendê-los de forma conjunta aos fatores geográficos do clima, dentre eles a altitude, latitude e circulação atmosférica, e demais elementos climáticos associados.

$\mathrm{Na}$ análise de agrupamento, considera-se como fundamental a definição preliminar de uma medida de similaridade entre os grupos a serem constituídos. Como as variáveis classificatórias utilizadas nesse estudo são variáveis reais e, portanto, são mensuradas em uma escala de intervalo, é conveniente adotar uma medida de distância com propriedades métricas, tendo sido escolhida a distância Euclidiana, por mostrar-se adequado às características das variáveis em consideração (KELLER FILHO et al., 2005; FRITZSONS et al., 2011). Adotou-se o método de ligação hierárquico Ward, que mensura a distância entre dois grupos pela soma de desvios ao quadrado dos pontos ao centróide e que tem a atribuição de um elemento a um grupo feito de modo a minimizar a soma dos quadrados dentro dos grupos (SILVESTRE et al., 2013).

Foi utilizado o software Statistica versão 7.0 para o processo de análise cluster e para a sua representação gráfica a partir da elaboração do gráfico denominando dendograma. O ponto de corte foi realizado em conformidade a interpretação dos resultados anuais e sazonais de pluviosidade, a proximidade espacial entre os postos pluviométricos e a estação meteorológica em relação às regiões identificadas e, principalmente, as características do relevo, considerado um dos principais fatores para a distribuição espacial da pluviosidade para a escala regional da área de estudo (CANDIDO e NUNES, 2009; CHIERICE e LANDIM, 2014).

O mapa com a hipsometria e regiões homogêneas foi elaborado a partir de informações extraídas de imagens SRTM (Shuttle Radar Topography Mission) do projeto TOPODATA (INPE, 2011), com resolução espacial de 30 metros, processadas no software ArcGis versão 10.3 (free trial). 


\section{RESULTADOS E DISCUSSÕES}

Os resultados da pluviosidade média anual para a vertente paranaense da bacia hidrográfica do rio Itararé indicaram que o setor sul apresenta uma pluviosidade média anual superior a $1.650 \mathrm{~mm}$, com o predomínio espacial de valores superiores a $1.500 \mathrm{~mm}$ (Figura 2A). Destaca-se que no setor sudoeste da bacia hidrográfica, de maiores cotas altimétricas, ocorre um aumento da pluviosidade média anual, com valores superiores a $1.500 \mathrm{~mm}$. Com uma redução significativa da altitude, o setor leste apresenta a menor média pluviométrica anual, inferior a $1.350 \mathrm{~mm}$. O predomínio de valores entre 1.400 e $1.600 \mathrm{~mm}$ para grande porção da bacia hidrográfica e um aumento da pluviosidade média anual para o setor sudeste, com valores entre 1.600 a $1.800 \mathrm{~mm}$, também foram verificados por Cavaglione et al. (2000).

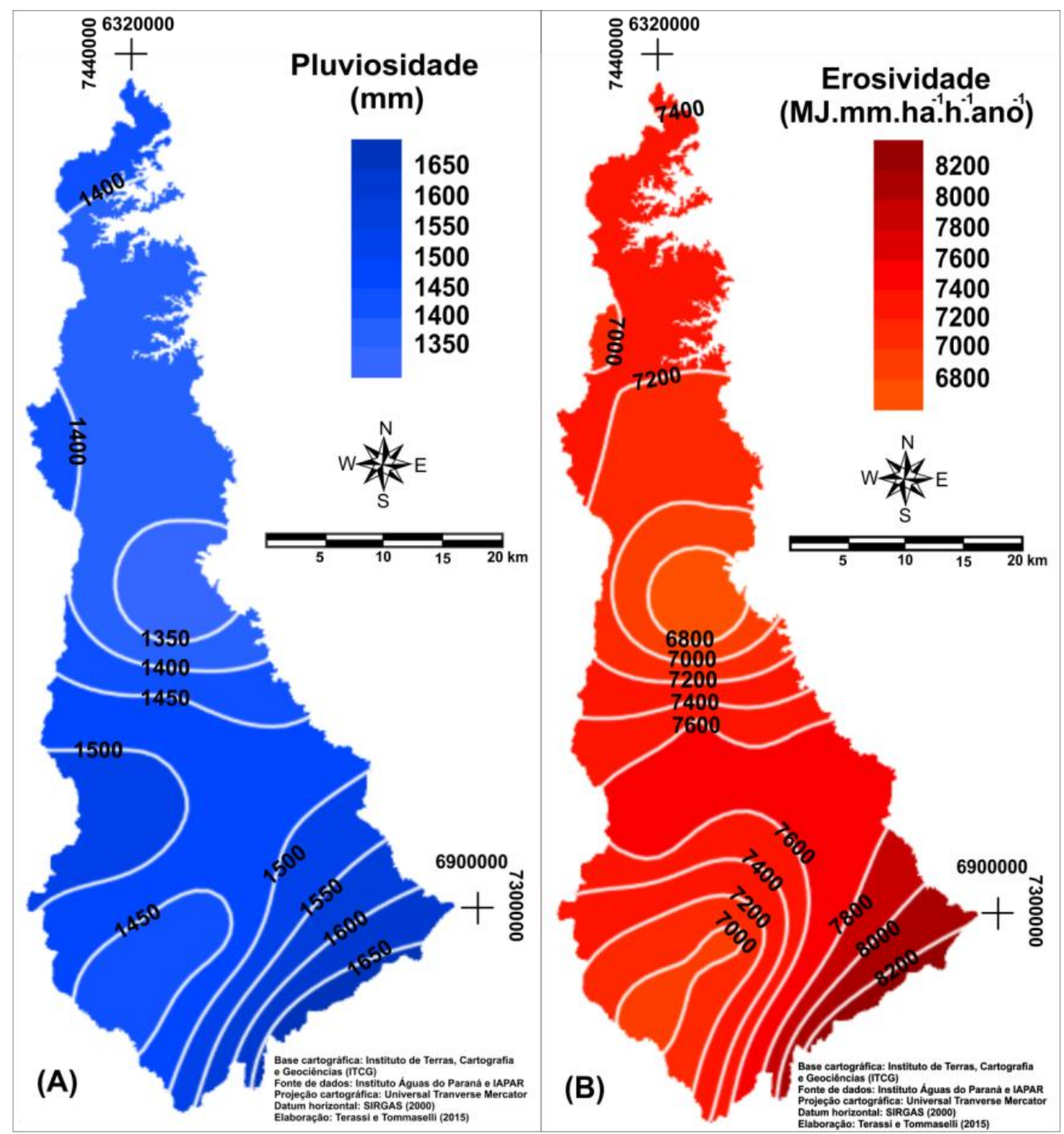

Figura 2: A) Distribuição espacial da pluviosidade média anual (mm); B) Erosividade média anual (MJ.mm.ha ${ }^{-1} \cdot h^{-1} \cdot$ ano $^{-1}$ ) para a vertente paranaense da bacia hidrográfica do rio Itararé.

A distribuição espacial dos valores do índice de erosividade obtidos permitiu a compreensão do potencial erosivo das chuvas para a vertente paranaense da bacia hidrográfica do rio Itararé. Observa-se que o setor sudeste apresentou as maiores erosividades média anual, com valores superiores a $8.200 \mathrm{MJ} \cdot \mathrm{mm} \cdot \mathrm{ha}^{-1} \cdot \mathrm{h}^{1}{ }^{1} \cdot \mathrm{ano}^{-1}$. O setor centro-leste apresenta a menor erosividade média anual, com índices de erosividade inferiores a $6.800 \mathrm{MJ} \cdot \mathrm{mm} \cdot \mathrm{ha}^{-1} \cdot \mathrm{h}^{-}{ }^{1}$. ano ${ }^{-1}$. Destaca-se que o setor sudoeste detém uma redução relevante da erosividade média anual em relação às demais porções da bacia hidrográfica, com valores inferiores a $7.000 \mathrm{MJ} \cdot \mathrm{mm} \cdot \mathrm{ha}^{-1} \cdot \mathrm{h}^{-1} \cdot \mathrm{ano}^{-1}$, o que se atribui principalmente a redução do volume de pluviosidade concentrada nos meses de verão e primavera para esta região da área de estudo (Figura 2B). 
Em comparação com a literatura mais recente, os resultados obtidos estão em desacordo com as isoerodentes obtidas para os setores do estado do Paraná em que está localizada a bacia hidrográfica do rio Itararé, visto que Waltrick et al. (2015) indicaram para o setor sul uma erosividade média anual inferior a $6.000 \mathrm{MJ} . \mathrm{mm} \cdot \mathrm{ha}^{-1} \cdot \mathrm{h}^{-}{ }^{1}$.ano ${ }^{-1}$, ao passo que para o setor norte apresentou resultados aproximados aos obtidos por estes mesmos autores, com isoerodentes superiores a 7.000 MJ.mm.ha ${ }^{-}$ ${ }^{1}$.h- ${ }^{1}$.ano ${ }^{-1}$. Estas diferenças se justificam pela quantidade dos pontos de coletas de dados selecionados, pois o trabalho relacionado exibe uma menor cobertura de postos pluviométricos para esta região e um recorte temporal inferior ao utilizado por esta pesquisa.

As características sazonais da pluviosidade demostraram que as estações mais chuvosas, verão e primavera, correspondem juntas a $63,4 \%$ da pluviosidade média anual para a bacia, com a maior representatividade registrada no verão, com uma média de pluviosidade equivalente a $502,9 \mathrm{~mm}$ ou $34,5 \%$ do volume médio anual. As duas estações menos chuvosas são o inverno e o outono, que somadas apresentam $36,6 \%$ da pluviosidade média anual. O inverno é a estação menos chuvosa, com valores médios de $259,3 \mathrm{~mm}$, que corresponde a $17,4 \%$ da média pluviométrica anual registrada na bacia (Figura 3).

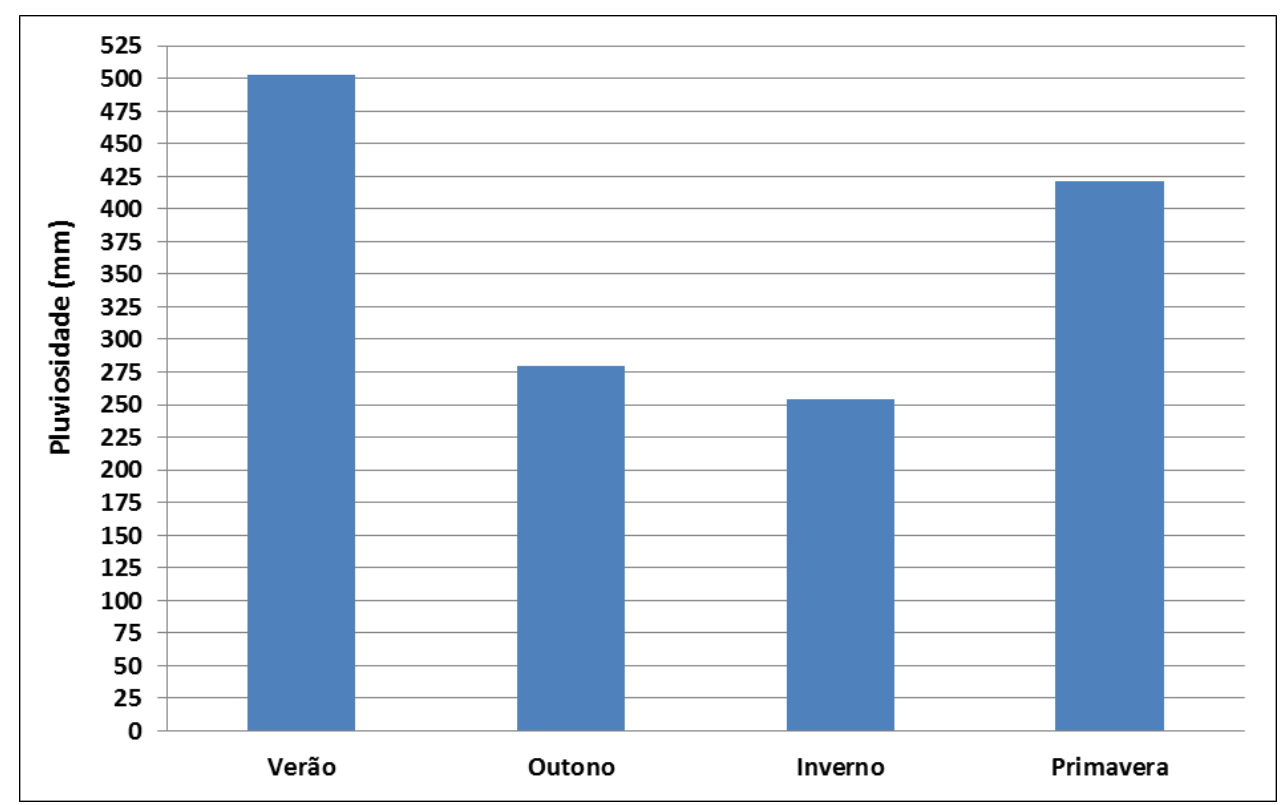

Figura 3: Distribuição da pluviosidade média sazonal para a estação meteorológica e os postos pluviométricos localizados no entorno e dentro da bacia hidrográfica do rio Itararé - PR.

A variação do volume de pluviosidade sazonal é controlada pela dinâmica atmosférica regional. Durante o período de verão e primavera destaca-se uma grande alternância dos diferentes fluxos destas massas de ar, sobretudo pelas seguintes condições: a intensificação da participação da atuação da massa Tropical atlântica, quando o aquecimento basal e o efeito orográfico ocasionado pelo contato com a superfície continental a tornam uma massa instável; a massa Equatorial continental atua de forma mais incisiva durante este período, que com sua expansão pelo continente responde pelo aumento de temperatura e umidade e, consequentemente, da pluviosidade; e a frente Polar atlântica, mecanismo atmosférico que antecede a massa Polar atlântica, que conjugada aos sistemas atmosféricos intertropicais, responde pelo aumento da instabilidade na região (NIMER, 1989; BALDO, 2006).

Além disso, o aumento de pluviosidade no verão também está associado a frequente formação da Zona de Convergência do Atlântico Sul (ZCAS), grande faixa de nebulosidade persistente que se estende do sul da Amazônia ao Atlântico Sul Central, no sentido sudeste a noroeste, e que ocasiona significativo volume de pluviosidade (QUADRO et al., 2012) e a formação das Linhas de Instabilidade Tropical, a partir da configuração atmosférica regional de umidade e temperaturas elevadas, propicia a ocorrência de eventos de elevada pluviosidade concentrada em um curto período (BEREZUK e SANT'ANNA NETO, 2006). A participação dos Complexos Convectivos de 
Mesoescala (CCM), mais frequente no outono e, sobretudo, na primavera, por vezes associadas à passagem de sistemas frontais, caracteriza-se por formar grande instabilidade por um período de 6 a 12 horas (VELASCO e FRITSCH, 1987).

A redução dos totais pluviométricos para o outono e inverno se atribui a menor participação dos sistemas intertropicais (massas tropicais e perturbações decorrentes), com uma maior dependência da frente Polar atlântica para a formação de instabilidade e a atuação diferenciada da massa Tropical atlântica, que com o resfriamento da superfície torna-se estável (BALDO, 2006; ZANDONADI, 2013; ZANDONADI et al., 2015).

Dessa forma, o verão é isoladamente a sazonalidade com a maior concentração do potencial erosivo anual, com uma média de 3.100,8 MJ.mm.ha ${ }^{-1} \cdot \mathrm{h}^{-1} \cdot$ sazonal $^{-1}$ ou a 42,3\% da erosividade média anual. Verificou-se que o inverno tem uma erosividade média de 978,3 MJ.mm.ha ${ }^{-1} \cdot \mathrm{h}^{-1} \cdot \mathrm{sazonal}^{-1} \mathrm{e}$ somente 13,4\% da média do índice anual de erosividade (Figura 4).

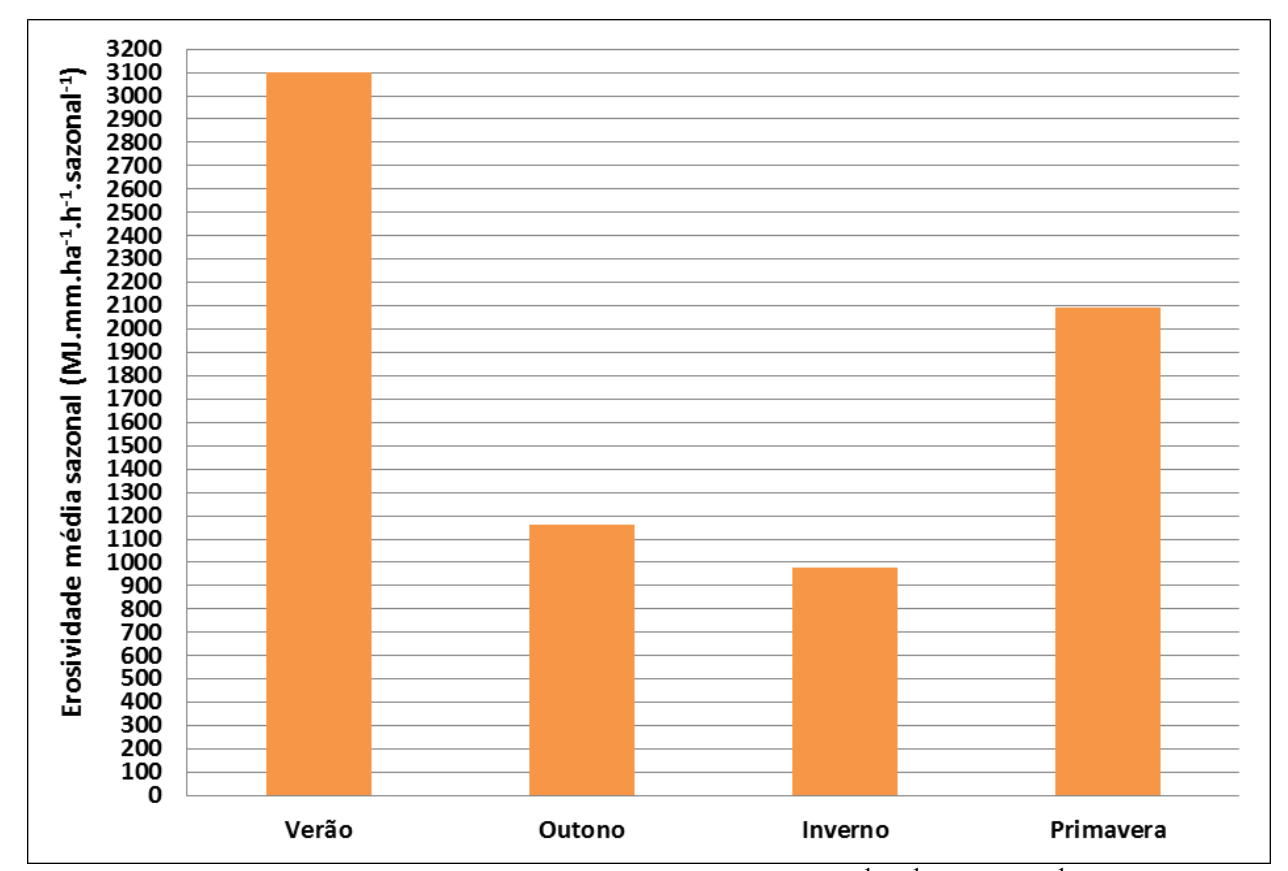

Figura 4: Distribuição sazonal da erosividade média $\left(\mathrm{MJ} \cdot \mathrm{mm} \cdot \mathrm{ha}^{-1} \cdot \mathrm{h}^{-1} \cdot\right.$ sazonal $\left.^{-1}\right)$ para a média da estação meteorológica e dos postos pluviométricos localizados no entorno e dentro da bacia hidrográfica do rio Itararé - PR.

A divisão sazonal do potencial erosivo das chuvas possibilita, portanto, observar notadamente a variação do regime pluviométrico, posto que as proporções são aumentadas com a aplicação da equação que mensura a erosividade das chuvas, como um ajuste para mensurar a intensidade pluviométrica. Ressalta-se que durante as estações chuvosas, com o aumento da temperatura e da umidade, é habitual que ocorra um aumento da convectividade e da participação de sistemas atmosféricos intertropicais, que caracterizam a ocorrências de maiores alturas pluviométricas e um consequente maior potencial erosivo. Durante o período de outono e de inverno, a redução das médias térmicas e a menor participação dos sistemas atmosféricos intertropicais indicam uma maior dependência da participação dos sistemas atmosféricos extratropicais para a ocorrência de chuvas, panorama que favorece a ocorrência de chuvas frontais, menos intensas e de menor potencial erosivo.

A setorização da área de estudo a partir da análise cluster a dividiu em quatro regiões homogêneas, considerando a importância do relevo e a sua relação com os mecanismos atmosféricos responsáveis pela gênese das chuvas, conforme apontam Candido e Nunes (2009), Milanesi e Galvani (2012) e Chierice e Landim (2014). A interpretação da dinâmica atmosférica regional, dada a partir da revisão literária (NIMER, 1989; BALDO, 2006; ZANDONADI, 2013; ZANDONADI et al., 2015), e as características do regime mensal da pluviometria e da erosividade permitiram estabelecer os mecanismos atmosféricos predominantes em cada uma das regiões homogêneas (Figura 5). 


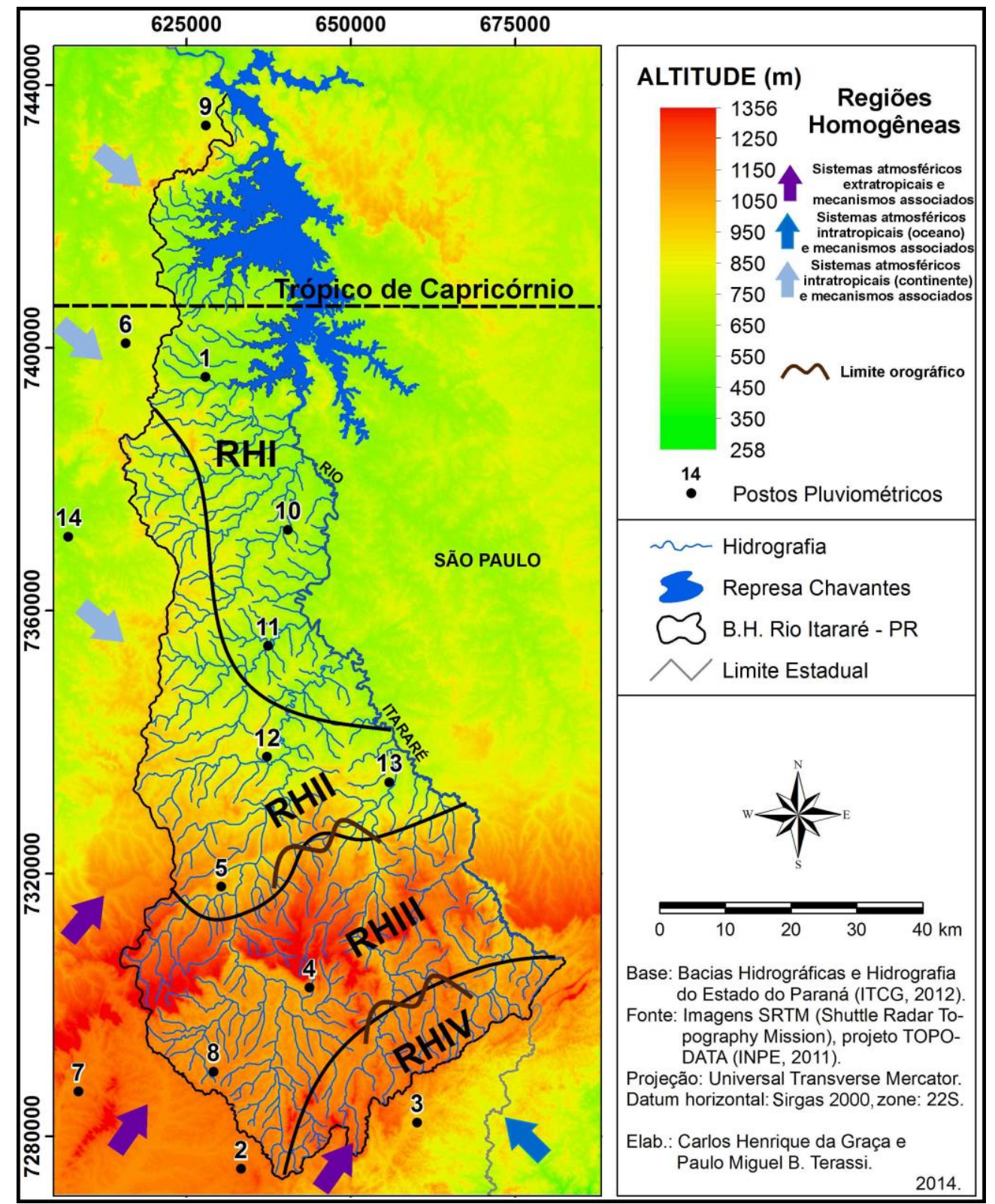

Figura 5: Distribuição espacial das regiões homogêneas para a pluviosidade e a erosividade das chuvas para a vertente paranaense da bacia hidrográfica do rio Itararé.

A primeira região homogênea localiza-se no setor norte da bacia hidrográfica, região de maior redução das chuvas nos meses de outono e inverno, sobretudo pela circulação atmosférica regional, mostrando, de forma geral, a menor média pluviométrica mensal. Este setor apresenta de forma mais notável a redução da orografia para a obtenção de menores valores de pluviosidade e a marcante característica de participação mais intensa dos sistemas atmosférica intertropical para a geração de chuvas e a redução da atuação dos sistemas atmosféricos extratropicais (Figura 6).

Verifica-se que para as regiões homogêneas II e III o fator orográfico não é significativo para a distribuição espacial dos volumes de pluviosidade, sendo que os maiores valores foram obtidos no para a região homogênea II. Comparativamente, mostrou-se que a região II apresentou maiores valores de pluviosidade para os meses de janeiro, fevereiro, março, novembro e dezembro, meses característicos de verão e primavera, ao passo que a região III obteve maiores alturas pluviométricos para os meses de outono e inverno. Essa condição demonstra que a região II se caracteriza por uma maior pluviosidade dentre as três regiões (I, II e III) por apresentar de forma mais significativa à interação entre sistemas atmosféricos intertropicais e extratropicais (Figura 6).

Excepcionalmente, a região IV corresponde à porção da bacia hidrográfica que apresenta as maiores médias de pluviosidade para todos os meses do ano, o que se atribui ao fato de que majoritariamente os sistemas atmosféricos extratropicais atuam de forma mais incisiva nesta região 
em relação aos demais setores da área de estudo. Ainda, explica-se que o fator orográfico é determinante para a ocorrência de maiores valores de pluviometria até determinada altitude, pois a formação de chuvas convectivas, por exemplo, ocorre com maior frequência a partir de maiores médias térmicas e maiores níveis de evapotranspiração (Figura 6).

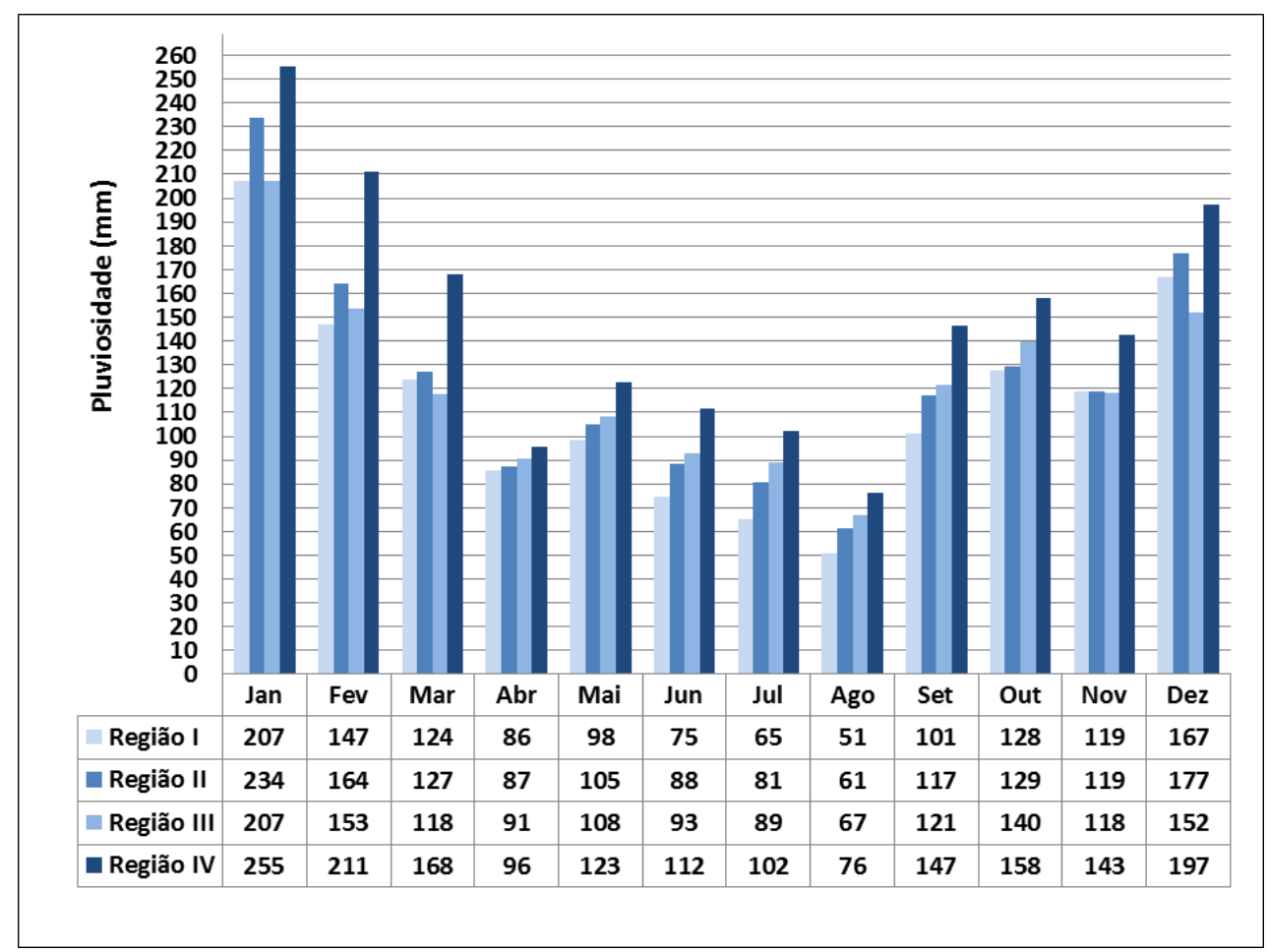

Figura 6: Distribuição mensal da pluviosidade $(\mathrm{mm})$ para as regiões homogêneas da vertente paranaense da bacia hidrográfica do rio Itararé.

O período que vai de janeiro a março e de setembro a dezembro apresenta uma concentração de $77,6 \%$ do potencial erosivo anual. O mês de janeiro é o que apresenta o maior potencial erosivo, com uma média de 1.659,1 MJ.mm.ha. ${ }^{-1} \mathrm{~h}^{-1} \cdot \mathrm{mês}^{-1}$, o que equivale a $22,6 \%$ da erosividade média anual. Inversamente, o mês de agosto é o que apresenta a menor erosividade média, correspondente a 1.94,5 MJ.mm.ha. ${ }^{-1}$ h. ${ }^{-1} \cdot$ mês $^{-1}$ e a 2,6\% do índice anual de erosividade para o recorte de estudo (Figura 7). A distribuição das médias mensais do potencial erosivo das chuvas para a vertente paranaense da bacia hidrográfica do rio Itararé está em conformidade com os resultados obtidos anteriormente por Waltrick et al. (2015) para o estado do Paraná, com valores mais elevados no período que vai de janeiro a março e de setembro a dezembro.

O período de janeiro a março e de setembro a outubro concentra o maior potencial erosivo para todos os grupos homogêneos, com uma relevante redução do índice de erosividade para o período de abril a agosto, principalmente para a região homogênea I, região de maiores similaridades com o regime de chuvas do Brasil Tropical. Os meses de maio e outubro apresentaram para as quatro regiões homogêneas um aumento de pluviosidade em relação aos meses antecessores e sucessores, ressaltando a tendência de aumento do volume de pluviosidade atrelado à atuação associada de sistemas atmosféricos de origens e conteúdos distintos, uma vez que esses meses se caracterizam pela transição de sazonalidades (Figura 7).

De modo geral, a região I obteve maiores valores de erosividade que a região III devido a sua distribuição mensal de sua pluviosidade, resultante das características atmosféricas aproximadas ao do Brasil Central, que delimitam uma tendência de maior concentração da pluviometria no período de verão e primavera. A região homogênea II apresenta um elevado potencial de erosividade das chuvas devido à interação mais constante entre os sistemas atmosféricos intertropicais e extratropicais (Figura 7). 
A região homogênea III caracteriza-se pela menor erosividade nos meses de verão e primavera dentre os grupos estabelecidos, e a menor diminuição dos índices de erosividade nos meses de outono e inverno, uma vez que os setores nos quais este grupo está localizado apresenta um regime pluviométrico que indica uma participação maior dos sistemas polares e, devido às menores médias térmicas, apresenta uma redução potencial de chuvas convectivas (Figura 7).

A região homogênea IV corresponde ao setor de maior erosividade das chuvas da área de estudo por localiza-se no limite de influência do efeito orográfico, apresentando maior potencialidade de chuvas convectivas em comparação à região homogênea III, resultante de maiores médias térmicas, e maiores valores de pluviosidade nos meses de outono e inverno em relação às regiões homogêneas I e II, por uma maior participação dos sistemas atmosféricos extratropicais (Figura 7).

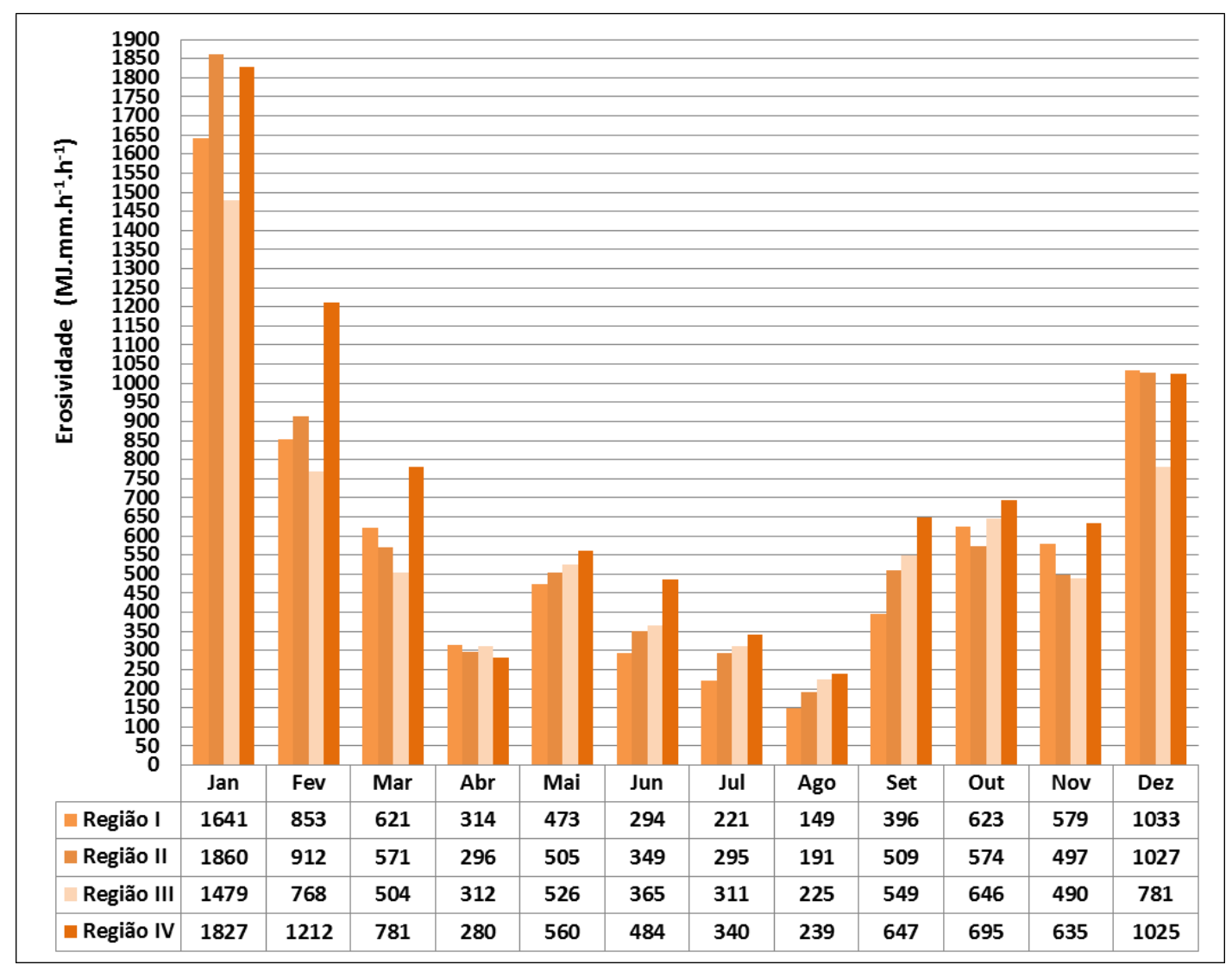

Figura 7: Distribuição mensal da erosividade média mensal $\left(\mathrm{MJ} \cdot \mathrm{mm}_{\mathrm{n}} \mathrm{ha}^{-1} \cdot \mathrm{h}^{1} \cdot \mathrm{mensal}^{-1}\right)$ para as regiões homogêneas da vertente paranaense da bacia hidrográfica do rio Itararé.

\section{CONSIDERAÇÕES FINAIS}

Embora tenha sido observado um certo padrão entre o efeito orográfico e o aumento de pluviosidade em determinados setores da bacia hidrográfica, conclui-se que a distribuição da pluviosidade para a escala anual está propriamente mais ligada às diferenças entre o regime pluviométrico sazonal e a interferência da dinâmica atmosférica regional. Identificou-se que as maiores alturas pluviométricas ocorrem durante o período que vai de outubro a março, correspondente ao verão e a primavera, que somadas concentram $63,4 \%$ do volume pluviométrico anual.

Os resultados obtidos a partir da aplicação do índice de erosividade das chuvas demonstrou uma distribuição espacial dos resultados satisfatórios quando associados ao regime pluviométrico sazonal, principalmente com a divisão em regiões homogêneas com a compreensão da dinâmica atmosférica regional e a sua relação com a orografia. $\mathrm{O}$ verão e a primavera caracterizam-se por apresentar a maior susceptibilidade potencial a erosividade das chuvas devido a uma concentração de $70,8 \%$ dos valores anuais de erosividade das chuvas. Dentre os resultados mais significativos, destaca-se que o mês de janeiro apresenta os maiores valores e que isoladamente apresenta $22,6 \%$ da erosividade média anual. Sobretudo, observou-se que as proximidades do reservatório de Chavantes 
apresentam a maior concentração de pluviosidade e, consequentemente, do potencial erosivo das chuvas para o período de outubro a março. Destaca-se que os meses de maio e outubro apresentam um aumento de pluviosidade em relação aos meses anteriores e sucessores em todas as regiões homogêneas devido à interação mais intensa entre sistemas atmosféricos extratropicais e intertropicais.

\section{REFERÊNCIAS}

ARAI, F. K.; GONÇALVES, G. G. G.; PEREIRA, S. B.; COMUNELLO, E.; VITORINO, A. C. T.; DANIEL, O. Espacialização da precipitação e erosividade na bacia hidrográfica do Rio Dourados - MS. Engenharia Agrícola, Jaboticabal, v. 30, n.5, p. 922-931, 2010.

BALDO, M.C. Variabilidade Pluviométrica e a Dinâmica Atmosférica da Bacia do Rio Ivaí. 2006. 153 f. Tese (Doutorado). Programa de Pós-Graduação em Geografia. Universidade Estadual Paulista "Júlio de Mesquita Filho", Presidente Prudente, 2006.

BEREZUK, A. G.; SANT'ANNA NETO, J. L. Eventos climáticos extremos no oeste paulista e no norte do Paraná nos anos de 1997, 1998 e 2001. Revista Brasileira de Climatologia, Curitiba, v. 2, n.1, p. 9-22, 2006.

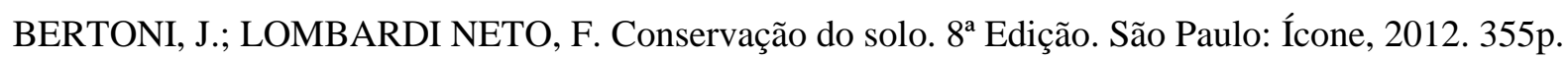

CABRAL, J. B. P.; BECEGATO, V. A.; SCOPEL, I.; LOPES, R. M. Técnicas de geoprocessamento na espacialização do potencial natural de erosão da chuva na bacia hidrográfica do reservatório de Cachoeira Dourada - GO/MG. RA’E GA: o Espaço Geográfico em Análise, Curitiba, v. 2, n.10, p. 1-18, 2005.

CABRAL, J.B.P.; BECEGATO, V.A.; ASSUNÇÃO, H.F.; RAFAELLI NETO, S.L. Monitoramento da erosividade na área do reservatório da hidroelétrica de Cachoeira Dourada, GO/MG. Geosul (UFSC), Florianópolis, v.22, n.44, p.47-65, 2007.

CANDIDO, D. H.; NUNES, L. H. Influência da orografia na precipitação da área entre o Vale do Rio Tiête e a Serra da Mantiqueira. Geousp (USP), São Paulo, v. 24, n.1, p. 08-27, 2009.

CARVALHO, J.R.P.; ASSAD, E.D. Análise espacial da precipitação pluviométrica no estado de São Paulo: comparação de métodos de interpolação. Engenharia Agrícola, Jaboticabal, v.25, n.2, p.377-384, 2005

CAVAGLIONE, J. H.; KIIHL, L. R. B.; CARAMORI, P. H.; OLIVEIRA, D. Cartas climáticas do Paraná. Londrina: IAPAR, 2000. CD ROM.

CHIERICE, R.A.F.; LANDIM, P.M.B. Variabilidade espacial e temporal de precipitação pluviométrica na bacia hidrográfica do rio Mogi Guaçu. Geociências, São Paulo, v.33, n.1, p.157-171, 2014.

DUKE ENERGY. Memórias. 2012. Disponível em: $<$ http://www.memoriaduke.com.br/Usinas.aspx?menu=8\&usina=3 $>$. Acesso em 06 de junho de 2016.

FOURNIER, F. Climat et erosion. Paris: Press Universitaries de France. 1960. 201p.

FRITZSONS, E.; MANTOVANI, L. E.; WREGE, M. S.; CHAVES NETO, A. Análise da pluviometria para definição de zonas homogêneas no estado do Paraná. RA'E GA: o Espaço Geográfico em Análise, v. 23, n.1, p. 555-572, 2011.

GARDIMAN JÚNIOR, B.S.; MAGALHÃES, I.A.L.; FREITAS, C.A.A.; CECÍLIO, R.A. Análise de técnicas de interpolação para espacialização da precipitação pluvial na bacia do rio Itapemirim (ES). Ambiência, Guarapuava, v.8, n.1, p.61-71, 2012.

GUERRA, A. J. T. O início do processo erosivo. In: GUERRA, A. J. T.; SILVA, A. S.; BOTTELHO, R. G. M. (org.). Erosão e Conservação dos Solos: Conceitos, Temas e Aplicações. $6^{a}$ Edição.Rio de Janeiro: Bertrand do Brasil. p. 17 - 50, 2010.

HUDSON, N. Soil conservation. Ithaca, New York, Cornell University Press, 1977. 320 p.

INPE (Instituto de Pesquisas Espaciais). Projeto TOPODATA. 2011. Disponível em: <http://www.dsr.inpe.br/topodata/>. Acesso em 22 de julho de 2014.

ITCG (Instituto de Terras, Cartografia e Geodésia). Produtos Cartográficos. Disponível em: $<$ http://www.itcg.pr.gov.br/modules/conteudo/. Acesso em 14 de julho de 2014. 
INÁCIO, E.S.B.; CANTALICE, J.R.B.; NACIF, P.G.S.; ARAUJO, Q.R.; BARRETO, A.C. Quantificação da erosão em pastagem com diferentes declives na microbacia do Ribeirão Salomea. Revista Brasileira de Engenharia Agrícola e Ambiental, Campina Grande, v.11, n.4, p.355-360, 2007.

KELLER FILHO, T; ASSAD, E.D.; LIMA, P.R.S.R. Regiões pluviometricamente homogêneas no Brasil. Revista Brasileira de Pesquisa Agropecuária, Brasília, v.40, n.4, p.311-322, 2005.

LEPRUN, J.C. A erosão, a conservação e o manejo do solo no Nordeste Brasileiro. Recife: SUDENEORSTOM. 1981. 104 p.

LOMBARDI NETO, F.; MOLDENHAUER, W. C. Erosividade da chuva: sua distribuição e relação com perdas de solo em Campinas, SP. Bragantia, Campinas, v.51, n.2, p. 189-196, 1992.

MAACK, R. Geografia Física do estado do Paraná. $4^{a}$ Edição. Ponta Grossa: Editora UEPG. 2012. 526p.

MARTINI, L.C.P.; UBERTI, A.A.A.;SCHEIBE, L.F.;COMIN, J.J.; ACCYOLI, M. Avaliação da suscetibilidade a processos erosivos e movimentos de massa: decisão multicriterial suportada em sistemas de informações geográficas. Geologia USP (Série Científica), São Paulo, v. 6, n.1, p. 41-52, 2006.

MILANESI, M. A.; GALVANI, E. Efeito orográfico na Ilha de São Sebastião (Ilhabela - SP). Revista Brasileira de Climatologia, Curitiba, v. 9, n.1, p. 68-79, 2012.

MIRANDA, R.B. A influência do assoreamento na geração de energia elétrica: Estudo de Caso na Usina Hidrelétrica de Três Irmãos - SP. 2011. 117f. Dissertação (Mestrado). Programa de Pós-Graduação em Ciências da Engenharia Ambiental, Escola de Engenharia de São Carlos, Universidade de São Paulo, São Carlos, 2011.

MORAIS, L.F. B.; NASCHENVENG, T.M; HARDOIN. P. C.; ALMEIDA, T.E.L.; WEBER, O L.; BOEL, E.; DURIGON, V. Índice EI 30 e sua relação com o coeficiente de chuva no Sudoeste do Mato Grosso. Revista Brasileira de Ciências do Solo, Campinas, v.15, n.3, 339-344, 1991.

NIMER. E. Climatologia do Brasil. 2ªEdição. Rio de Janeiro: Instituto Brasileiro de Geografia e Estatística, 1989. 421p.

OLIVEIRA, L.F.C.; FIOREZE, A.P.; MEDEIROS, A.M.M.; SILVA, M.A.S. Comparação de metodologias de preenchimento de falhas em séries históricas de precipitação pluvial anual. Revista Brasileira de Engenharia Agrícola e Ambiental, Campina Grande, v.14, n.11, p.1186-1192, 2010.

OLIVEIRA, P.T.S.; WENDLAND, E.; NEARING, M.A. Rainfall erosivity in Brazil: a review. Catena, Amsterdam, v. 100, p.139-147, 2012.

QUADRO, M. F. L.; SILVA DIAS, M. A. F.; HERDIES, D. L.; GONCALVES, L. G. G. Análise climatológica da precipitação e do transporte de umidade na região da ZCAS através da nova geração de reanálises. Revista Brasileira de Meteorologia, São Paulo, v. 27, n.2, p. 287-294, 2012.

RUBIO, M.F. Gênese e dinâmica de erosões em margens de reservatórios. Pesquisa e Desenvolvimento no estudo de caso nas UHEs Chavantes e Rosana (rio Paranapanema, SP/BR). 2014. 255f. Tese (Doutorado). Programa de Pós-Graduação em Geografia Física, Universidade de São Paulo, São Paulo, 2014.

RUFINO, R. L.; BISCAIA, R. C. M.; MERTEN, G. H. Determinação do potencial erosivo da chuva do estado do Paraná, através de pluviometria: terceira aproximação. Revista Brasileira de Ciência do Solo, Campinas, v. 17, n.1, p. 439-444,1993.

SILVA, A.M. Rainfall erosivity map for Brazil. Catena, Amsterdam, v.57, n.3, p.251-259. 2004.

SILVA, M.A.; SILVA, M.L.N.; CURI, N.; SANTOS, G.R.; MARQUES, J.J.G.S.M.; MENEZES, M.D.; LEITE, F.P. Avaliação e espacialização da erosividade da chuva no Vale do rio Doce, região Centro-Leste do Estado de Minas Gerais. Revista Brasileira de Ciência do Solo, Viçosa, v.34, n.4, p.1029-1039, 2010.

SILVESTRE, M. R.; SANT'ANNA NETO, J. L.; FLORES, E. F. Critérios estatísticos para definir anos padrão: uma contribuição à Climatologia Geográfica. Revista Formação, Presidente Prudente, v. 2, n.20, p. 23-53, 2013.

STOCKING, M.A. Rainfall erosivity in erosion: some problems and applications. In: Research Discussion Paper. Edinburgh: Edinburgh University, Department of Geography, v.13, 1977. 29p.

TOYAMA, I. T. A experiência da gestão sócio-patrimonial da Duke Energy em reservatórios no rio Paranapanema. Caderno Prudentino de Geografia, Presidente Prudente, Volume especial, n.36, p.256-297, 2014. 
UFOEGBUENE, G.C; BELLO, N.J.; OJEKUNLE, Z.O.; ORUNKOYE, A.R.; ERUOLA, A.O.; AMORI, A.A. Rainfall erosivity pattern of Ogun river basin area (Nigeria) using modified Fournier Index. European Water, Athens, v.35, n.1, p.23-29, 2011.

VILLELA, S. M.; MATTOS, A. Hidrologia aplicada. São Paulo: McGraw-Hill do Brasil, 1975. 245p.

VELASCO, I.; FRITSCH, J. M. Mesoscale convective complexes in the Americas. Journal of Geophysical Research, Washington, v. 92, n.8, p. 9591-9613, 1987.

WALTRICK, P. C.; MACHADO, M. A. M.; DIECKOW, J.; OLIVEIRA, D. Estimativas da erosividade de chuvas no estado do Paraná pelo método da pluviometria: Atualização com dados de 1986 a 2008. Revista Brasileira de Ciência do Solo, Viçosa, v.39, n.1, p.256-267, 2015.

WISCHMEIER, W. H.; SMITH, D. D. Rainfall energy and its relationship to soil loss. Transactions of the American Geophysical Union, Washington, v.39, n.2, p.285-291, 1958.

ZANDONADI, L. As chuvas da bacia do rio Paraná, Brasil: Um estudo do ritmo climático e algumas considerações sobre a vazão hídrica. 2013. 206f. Tese (Doutorado). Programa de Pós-Graduação em Geografia, Universidade Estadual Paulista "Júlio de Mesquita Filho", Rio Claro, 2013.

ZANDONADI, L.; ACQUAOTTA, F.; FRATIANNI, S.; ZAVATTINI, J. A. Changes in precipitation extremes in Brazil (Paraná River Basin). Theoretical and Applied Climatology, New York, v. 119, n.1, p. 01$18,2015$.

ZHANG, G.H.; NEARING, M.A.; LIU, B.Y. Potencial effects of climate change on rainfall erosivity in the Yellow river basin of China. Transactions of the American Society of Agriculture Engineers, Washington, v.48, n.2, p.511-517, 2005. 